\title{
Aspectos clínicos, patogênese e diagnóstico de Trichomonas vaginalis
}

\author{
Clinical aspects, pathogenesis and diagnostic of Trichomonas vaginalis
}

Gisele de Paiva Maciel'; Tiana Tasca ${ }^{1,2}$; Geraldo Attilio De Carli ${ }^{3}$

\section{unitermos}

Trichomonas vaginalis

Vaginite

Corrimento vaginal

DST

Diagnóstico

\section{resumo}

Trichomonas vaginalis é o agente etiológico da tricomoníase, a doença sexualmente transmissível (DST) não-viral mais comum no mundo. Esse protozoário flagelado atinge o parasitismo com sucesso em um ambiente hostil através dos vários mecanismos pelos quais estabelece sua patogenicidade e também por sua capacidade de evadir a resposta imune do hospedeiro. A infecção apresenta uma ampla variedade de manifestações clínicas, desde quadro assintomático até severa vaginite. A tricomoníase tem sido associada à transmissão do vírus da imunodeficiência humana (HIV), à doença inflamatória pélvica, ao câncer cervical, à infertilidade, ao parto prematuro e ao baixo peso de bebês nascidos de mães infectadas. A investigação laboratorial é essencial na diagnose dessa patogenia, uma vez que leva ao tratamento apropriado e facilita o controle da propagação da infecção. A prevalência mundial anual da tricomoníase é de 180 milhões de casos, e na Europa é responsável por $41 \%$ dos casos de vaginite. A terapia da tricomoníase inclui as mesmas medidas profiláticas destinadas às outras DSTs, como prática de sexo seguro e uso de preservativos. O metronidazol é o medicamento de escolha no tratamento da tricomoníase, entretanto, devido à ineficácia dos tratamentos de dose única e ao iminente surgimento de cepas resistentes, outras alternativas terapêuticas estão sendo investigadas.
Trichomonas vaginalis is the aethiologic agent of trichomoniasis, the sexually transmitted disease (STD) non-viral most common in the world. This flagellate protozoan successfully reaches the parasitism in a hostile environment through some mechanisms which establish its pathogenicity and also through its capacity to evade the host immune response. Trichomoniasis presents a large variety of clinical manifestations, from a totally asymptomatic infection to severe vaginitis. It has been associated to the increase in transmission of the human immunodeficiency virus (HIV), pelvic inflammatory disease, cervical cancer, infertility, and premature delivery and low birth weight of children born from infected mothers. The laboratorial inquiry is essential in diagnosis of this STD, leads to the appropriate treatment and facilitates the control of the spread of T. vaginalis infection. The annual world prevalence of trichomoniasis is 180 million cases and in Europe it is responsible for $41 \%$ of vaginitis cases. The treatment of trichomoniasis includes the same profilatic means devoted to others STDS, such as secure sex practice and preservative use. Metronidazole is the choose for the treatment of trichomoniasis, however, due to the fail in the single dose treatment and the imminent appearance of resistant strains, other therapeutic alternatives are been investigated.
1. Farmacêutica-bioquímica do Laboratório de Parasitologia Clínica da Faculdade de Farmácia da Pontifícia Universidade Católica do Rio Grande do Sul (PUCRS).
2. Doutoranda em Ciências Biológicas/Bioquímica na Universidade Federal do Rio Crande do Sul (UFRCS).
3. Doutor em Farmácia e Bioquímica pela UFRCS; professor-titular de Parasitologia Clínica do Laboratório de Parasitologia Clínica da Faculdade de Farmácia da PUCRS. key words Trichomonas vaginalis

Vaginitis Vaginal discharge STD Diagnosis 


\section{Introdução}

Trichomonas vaginalis é o causador da doença sexualmente transmissível (DST) não-viral mais comum no mundo. A Organização Mundial da Saúde (OMS) estimou em 170 milhões os casos de tricomoníase no mundo anualmente em pessoas entre 15 e 49 anos, com a maioria (92\%) ocorrendo em mulheres ${ }^{(19)}$. Apesar da alta prevalência e dos riscos associados à tricomoníase, pouco é conhecido sobre a variabilidade biológica do parasito ${ }^{(5)}$. O T. vaginalis não é grande causador de seqüelas e, por isso, muitos clínicos têm considerado a doença mais um incômodo do que um problema de saúde pública(6). Entretanto o T. vaginalis tem se destacado como um dos principais patógenos do homem e da mulher e está associado a sérias complicações de saúde ${ }^{(29)}$. Publicações recentes mostraram que o $T$. vaginalis promove a transmissão do vírus da imunodeficiência humana (HIV) $)^{(17,41)}$; é causa de baixo peso em bebês, bem como de nascimentos prematuros ${ }^{(9)}$; predispõe mulheres a doença inflamatória pélvica atípica ${ }^{(22)}$, câncer cervical $^{(20,25,43)}$ e infertilidade ${ }^{(21)}$.

A tricomoníase apresenta uma ampla variedade de manifestações clínicas. Os sinais e sintomas dependem das condições individuais, da agressividade e do número de parasitos infectantes. Pode haver sintomas de severa inflamação e irritação da mucosa genital, com presença de corrimento, o que leva a paciente a procurar o médico. Outras vezes a tricomoníase é assintomática e, ocasionalmente, descoberta em um exame de rotina ${ }^{(31,35)}$.

Embora a doença tenha sido diagnosticada e o protozoário descrito em 1836, o diagnóstico clínico e laboratorial da tricomoníase, especialmente em homem, continua apresentando inúmeras dificuldades. Um diagnóstico clínico diferencial dessa doença, tanto no homem como na mulher, dificilmente poderá ser realizado através de sintomas e sinais específicos. A investigação laboratorial é essencial na diagnose dessa patogenia, permitindo também diferenciá-la de outras doenças sexualmente transmissíveis. O tratamento da tricomoníase é específico e eficiente, por isso tornam-se essenciais a identificação e o tratamento das pessoas infectadas, evitando-se assim a transmissão sexual do parasito(10, 14).

\section{0 parasito}

$O T$. vaginalis é uma célula tipicamente elipsóide, piriforme ou oval em preparações fixadas e coradas. As condições físico-químicas (por exemplo: pH, temperatura, tensão de oxigênio e força iônica) afetam o aspecto dos organismos, que não possuem a forma cística, somente a trofozoítica. $\mathrm{O} T$. vaginalis possui quatro flagelos anteriores, desiguais em tamanho, e uma membrana ondulante que se adere ao corpo pela costa. O axóstilo é uma estrutura rígida e hialina, formada por microtúbulos, que se projeta através do centro do organismo, prolongando-se até a extremidade posterior. O núcleo é elipsóide, próximo à extremidade anterior. Esse protozoário é desprovido de mitocôndrias, mas apresenta grânulos densos que podem ser vistos ao microscópio óptico, os hidrogenossomos ${ }^{(13,35)}$.

O T. vaginalis é um organismo anaeróbio facultativo. Cresce perfeitamente bem na ausência de oxigênio na faixa de $\mathrm{pH}$ compreendida entre 5 e 7,5 e em temperaturas entre $20^{\circ} \mathrm{C}$ e $40^{\circ} \mathrm{C}$. Como fonte de energia, o flagelado utiliza a glicose, a maltose, a galactose. Os hidrogenossomos são portadores de uma enzima piruvato: ferredoxina oxidorredutase, capaz de transformar o piruvato em acetato pela oxidação fermentativa e liberar adenosina 5 '-trifosfato (ATP) e hidrogênio molecular. O T. vaginalis é capaz de manter o glicogênio em reserva como forma de energia ${ }^{(13)}$. Isso é importante para o parasito, pois o ambiente vaginal é constantemente modificado por variações de $\mathrm{pH}$, hormônios, menstruação e fornecimento de nutrientes. Os carboidratos são a principal fonte de nutrientes para o $T$. vaginalis; no entanto, sob condições em que tais compostos são limitados, a utilização de aminoácidos torna-se vital. O T. vaginalis consome especialmente arginina, treonina e leucina ${ }^{(35)}$.

\section{Manifestações clínicas}

\section{Na mulher}

$O T$. vaginalis infecta principalmente o epitélio escamoso do trato genital ${ }^{(29)}$. A tricomoníase apresenta grande variabilidade de manifestações patológicas, desde a apresentação assintomática até um estado de severa inflamação (vaginite) $^{(5)}$. Das mulheres infectadas, entre $25 \%$ e $50 \%$ são assintomáticas, têm pH vaginal normal de 3,8 a 4,2 e flora vaginal normal ${ }^{(35)}$. Um terço das pacientes assintomáticas torna-se sintomático dentro de seis meses ${ }^{(29)}$. É uma doença de idade reprodutiva e raramente as manifestações clínicas da infecção são observadas antes da menarca ou após a menopausa ${ }^{(35)}$.

Mulheres com vaginite aguda causada por $T$. vaginalis freqüentemente têm corrimento devido a infiltração por leucócitos. A consistência do corrimento varia de acordo 
com a paciente, de fino e escasso a espesso e abundante. O sintoma clássico de corrimento amarelo, abundante, espumoso e mucopurulento ocorre em somente $20 \%$ dos $\operatorname{casos}^{(29)}$. Há também odor vaginal anormal e prurido vulvar. A vagina e a cérvice podem ser edematosas e eritematosas, com erosão e pontos hemorrágicos na parede cervical conhecidos como colpitis macularis ou cérvice com aspecto de morango. Embora essa aparência seja altamente específica para tricomoníase, é vista somente em poucas mulheres (2\% a 5\%). Dor abdominal tem sido relatada entre muitas mulheres com tricomoníase e pode ser indicativa de infecção do trato urogenital superior ${ }^{(20,29,43)}$.

A severidade da tricomoníase pode também induzir estados citopatológicos de displasia/metaplasia(31) já que a infecção foi detectada freqüentemente (39\%) em mulheres com neoplasia intra-epitelial cervical $(\mathrm{CIN})^{(20,25)}$.

Recentes publicações indicam que o impacto da tricomoníase não é limitado a vaginites - micoplasmas e Neisseria gonorrhoeae são fagocitados por T. vaginalis, e segmentos de RNA viral têm sido encontrados em certas linhagens do parasito. É possível, então, que o protozoário possa atuar também como vetor para outros patógenos ${ }^{(9)}$.

Na infecção crônica, os sintomas são leves, com secreção vaginal escassa. Essa forma é particularmente importante do ponto de vista epidemiológico, pois esses indivíduos são a maior fonte de transmissão do parasito(35).

\section{No homem}

Diferentemente da mulher, homens infectados pelo contato com parceira sexual infectada, por razão desconhecida podem ter somente infecção autolimitada(29).

A tricomoníase em homens pode ser classificada em três grupos: estado assintomático; estado agudo, caracterizado por uretrite purulenta abundante; e doença assintomática leve, clinicamente indistinguível de outras causas de uretrite ${ }^{(35)}$.

No estado sintomático há escasso corrimento, disúria, prurido, ulceração peniana ${ }^{(6)}$ e sensação de queimação imediatamente após a relação sexual. Complicações são raras, mas podem incluir epididimite, infertilidade e prostatite $^{(35)}$.

Muitos homens com idade entre 16 e 22 anos apresentaram-se positivos para tricomoníase quando submetidos a massagem prostática. Dessa forma, o exame do sedimento urinário, rotineiramente utilizado para o diagnóstico de tricomonas em homens, pode induzir falsos resultados se não for acompanhado de massagem prostática(31).
A significância clínica da tricomoníase em homens parece ser controversa, visto que muitos homens infectados são assintomáticos. No entanto, foi observada inflamação uretral com uretrite não-gonocócica. O zinco é altamente tóxico para $T$. vaginalis, e é possível que muitos homens refratários a esta infecção tenham quantidades consideráveis deste metal no fluido prostático ${ }^{(31)}$.

\section{Patogênese}

\section{Problemas relacionados com a gravidez}

Parto prematuro e baixo peso ao nascer representam problemas de saúde pública nos EUA, particularmente entre mulheres negras. Grávidas infectadas por $T$. vaginalis têm alto risco de desenvolver complicações na gravidez. Estudos têm relatado associação entre tricomoníase e ruptura prematura de membrana, parto prematuro, baixo peso ao nascer, endometrite pós-parto, feto natimorto e morte neonatal. A resposta inflamatória gerada pela infecção por $T$. vaginalis pode conduzir direta ou indiretamente a alterações na membrana fetal ou decídua ${ }^{(9)}$.

Embora a infecção por T. vaginalis seja comum entre mulheres grávidas, o exame de cultura não é comumente realizado a partir de neonatos nem é um patógeno altamente suspeito em berçários de cuidados intensivos. Contudo recém-nascidas com corrimento vaginal têm sido relatadas como infectadas por T. vaginalis(23).

\section{Problemas relacionados com a fertilidade}

Adesão e oclusão tubária são estimadas como as causas de aproximadamente $20 \%$ dos casos de infertilidade em países desenvolvidos. O risco de infertilidade é quase duas vezes maior em mulheres com história de tricomoníase, em comparação com as que nunca tiveram tal infecção(21).

O T. vaginalis está relacionado com doença inflamatória pélvica, pois infecta o trato urinário superior, causando resposta inflamatória que destrói a estrutura tubária, e danifica as células ciliadas da mucosa tubária, inibindo a passagem de espermatozóides ou óvulos através da tuba uterina. Mulheres com mais de um episódio de infecção relatado têm maior risco de infertilidade do que aquelas que tiveram um único episódio. Para mulheres com o primeiro episódio antes dos 21 anos, esse risco é duas vezes maior do que para aquelas com o primeiro episódio depois dos $21 \operatorname{anos}^{(21)}$. 


\section{Transmissão do HIV}

$\mathrm{O}$ T. vaginalis pode ter um papel crítico na amplificação da transmissão do HIV. É um importante co-fator na propagação do vírus e causa grande impacto sobre a epidemia de HIV nas comunidades afro-americanas ${ }^{(41)}$. O risco de transmissão de HIV aumenta na presença de doença ulcerativa genital e de doença não-ulcerativa, como a tricomoníase ${ }^{(25)}$.

A infecção por T. vaginalis tipicamente faz surgir uma agressiva resposta imune celular local com inflamação do epitélio vaginal e da exocérvice em mulheres e da uretra em homens. Essa resposta inflamatória induz uma grande infiltração de leucócitos, incluindo células-alvo do HIV, como linfócitos TCD4+ e macrófagos, aos quais o HIV pode se ligar e ganhar acesso. Além disso, o T. vaginalis freqüentemente causa pontos hemorrágicos na mucosa, permitindo o acesso direto do vírus à corrente sangüínea. Desse modo, há um aumento na porta de entrada para o vírus em indivíduos HIV-negativos. Similarmente, em uma pessoa infectada pelo HIV, os pontos hemorrágicos e a inflamação podem aumentar os níveis de vírus nos fluidos corporais e o número de linfócitos e macrófagos infectados pelo HIV presentes na região genital. Isso resulta em aumento de vírus livres e ligados aos leucócitos, expandindo a porta de saída do HIV. Desse modo, há uma probabilidade oito vezes maior de exposição e transmissão em parceiro sexual não-infectado(41).

Além disso, aumento da carga viral na secreção uretral tem sido documentado em indivíduos com tricomoníase ${ }^{(41)}$. Aumento na secreção de citocinas (interleucinas 1, 6, 8 e 10), conhecidas por aumentar a suscetibilidade ao HIV, está sendo agora demonstrado durante a tricomoníase ${ }^{(29)}$. O T. vaginalis tem capacidade de degradar o inibidor de protease leucocitária secretória, um produto conhecido por bloquear o ataque do HIV às células, e este fenômeno também pode promover a transmissão do vírus. Em adição, muitos pacientes são assintomáticos e, mantendo-se sexualmente ativos, propagam ainda mais a infecção $0^{(41)}$. Essas descobertas sugerem que o diagnóstico e o tratamento para a infecção por $T$. vaginalis em homens e mulheres podem reduzir significativamente a transmissão do $\mathrm{HIV}^{(6)}$.

\section{Mecanismos da patogênese}

$\mathrm{O}$ estabelecimento de $T$. vaginalis na vagina se inicia com o aumento do $\mathrm{pH}$, já que o $\mathrm{pH}$ normal da vagina é ácido $(3,8$ a 4,5) e o organismo cresce em $\mathrm{pH}$ maior que 5. A elevação do $\mathrm{pH}$ vaginal na tricomoníase é evidente, com redução concomitante de Lactobacillus acidophilus e aumento na proporção de bactérias anaeróbias ${ }^{(35)}$.
As respostas imunes celular e humoral são evidentes em pacientes com tricomoníase. Embora não seja encontrado em todos os pacientes com tricomoníase, o aumento no número de leucócitos polimorfonucleares pode ser detectado facilmente nas secreções. Um contato inicial entre $T$. vaginalis e leucócitos resulta em formação de pseudópodes, em internalização e em degradação das células imunes nos vacúolos fagocitários do parasito(29).

A interação entre o T. vaginalis e o seu hospedeiro é um processo complexo, no qual estão envolvidos componentes associados à superfície celular do parasito, células epiteliais do hospedeiro e também componentes solúveis encontrados nas secreções vaginal e uretral. A aderência e a citotoxicidade exercidas pelos parasitos sobre as células do hospedeiro podem ser ditadas pelos fatores de virulência, como adesinas, cisteína-proteinases, integrinas, cell-detaching factor (CDF) e glicosidases. O T. vaginalis necessita aderir às células hospedeiras para exercer seus efeitos patogênicos. Porém a possibilidade de exercer essa atividade em cultura de células epiteliais na ausência de citoaderência merece ser considerada, já que produtos secretados pelos parasitos, como glicosidases e CDF, em meios de cultura, têm se mostrado altamente tóxicos a células epiteliais ${ }^{(31)}$.

Quatro proteínas (adesinas) têm sido identificadas como mediadoras da citoaderência: AP23, AP33, AP51 e AP65 (1). A síntese dessas proteínas é regulada positivamente pela ligação a células epiteliais e pelo ferro(2, 18). A expressão de adesinas na superfície do parasito é alternada com a expressão de P270, uma proteína altamente imunogênica. Essa alternância na expressão parece ser um mecanismo utilizado pelo parasito para evadir o sistema imune ${ }^{(31)}$.

Outra classe de moléculas implicadas na adesão de T. vaginalis é representada por cisteína-proteinases, que são citotóxicas e hemolíticas e apresentam capacidade de degradar IgG, IgM e IgA presentes na vagina ${ }^{(31,35)}$. O funcionamento das proteinases de superfície também é modulado pelo ferro ${ }^{(31)}$. O papel desempenhado pelo ferro nas infecções tem sido extensamente revisado( $29,31,35)$. Em casos de microorganismos que são encontrados em ambientes de baixo potencial redox, o ferro também tem papel crucial na sobrevivência destes organismos. Em adição, os mecanismos de defesa desempenhados pelos tricomonas contra o estresse oxidativo gerado pelos radicais superóxidos estão centrados na atividade superóxido dismutase (SOD), que necessita de ferro como co-fator ${ }^{(31)}$.

Hemácias podem ser fagocitadas pelo $T$. vaginalis para a aquisição de ferro da hemoglobina e também como fonte 
de ácidos graxos, já que o parasito é incapaz de sintetizar lípideos(28). A hemólise pode ser mediada pela inserção de poros na membrana da hemácia, formados pela liberação de proteínas do tipo perforinas (possivelmente cisteína-proteinases) ou através da interação entre receptores eritrocitários e adesinas do parasito, o que provoca a aderência entre as células e a eritrofagocitose pelo protozoário ${ }^{(31,37,40)}$.

Embora os mecanismos contato-dependentes tenham um papel significante na patogênese da tricomoníase, mecanismos contato-independentes estão também envolvidos. Hemólise e citotoxicidade, por exemplo, não podem ser explicados somente pelos mecanismos contato-dependentes, já que esses efeitos podem ser vistos na ausência de contato célula/célula. Estudos demonstraram que o CDF causa efeitos citopatogênicos em células cultivadas in vitro. Os níveis de CDF podem ser correlacionados com a severidade dos sintomas clínicos da vaginite. A produção de CDF é influenciada pela concentração de estrógenos na vagina, visto que, in vitro, a produção de CDF pelos tricomonas diminui na presença de $\beta$-estradiol. Isso pode explicar por que a aplicação de pellets de estradiol intravaginais parece melhorar os sintomas sem erradicar a infecção ${ }^{(35)}$.

$O T$. vaginalis ativa a via alternativa do complemento. O muco cervical é deficiente em complemento e o sangue menstrual representa a única fonte de complemento na vagina. Enquanto o número de organismos na vagina diminui durante a menstruação, os fatores de virulência mediados pelo ferro contribuem para a exacerbação dos sintomas neste período. O ferro contribui para a resistência ao complemento por regular a expressão de cisteína-proteinases, que degradam a porção C3 do complemento depositada sobre a superfície do organismo. Além disso, o T. vaginalis pode se auto-revestir de proteínas plasmáticas do hospedeiro. Esse revestimento impede que o sistema imune reconheça o parasito como estranho ${ }^{(35)}$.

\section{Diagnóstico}

O diagnóstico da tricomoníase não pode ser baseado somente na apresentação clínica, pois a infecção poderia ser confundida com outras DSTs, visto que o clássico achado da cérvice com aspecto de morango é observado somente em $2 \%$ das pacientes, e o corrimento espumoso, em somente $20 \%$ das mulheres infectadas. Se a clínica fosse utilizada isoladamente para o diagnóstico, $88 \%$ das mulheres infectadas não seriam diagnosticadas e $29 \%$ das não-infectadas seriam falsamente indicadas como tendo infecção. A investigação laboratorial é necessária e essencial para o diagnóstico da tricomoníase, uma vez que leva ao tratamento apropriado e facilita o controle da propagação da infecção ${ }^{(35)}$.

O exame de amostras vaginal e cervical pode revelar alterações citomorfológicas induzidas pelos tricomonas. $\mathrm{O}$ esfregaço é tipicamente rico em elementos polimorfonucleares e há grande número de células epiteliais isoladas ${ }^{(8,31)}$.

Muitos desses estudos têm utilizado freqüentemente técnicas com relativamente baixa sensibilidade, como o exame direto a fresco e preparações coradas, e, conseqüentemente, a prevalência de infecção por $T$. vaginalis pode ser subestimada ${ }^{(41)}$.

O método de cultura é o padrão-ouro para o diagnóstico porque é simples de interpretar e requer somente $300 \mathrm{a}$ 500 tricomonas/ml de inóculo para iniciar o crescimento. No entanto, são necessários alguns dias para a identificação do parasito, tempo durante o qual os pacientes infectados podem continuar a transmitir a infecção ${ }^{(12,15,35,39)}$. O sistema de cultura InPouchTV, sensível como o método de cultura tradicional, tem se mostrado uma alternativa eficiente e de baixo custo ${ }^{(14,33)}$.

Outra alternativa seria primeiro fazer uma triagem pelo exame a fresco, que é relativamente fácil e rápido, seguida pela cultura das amostras que foram negativas por tal exame ${ }^{(41)}$. Quando o exame microscópico é positivo, a terapêutica apropriada poderá ser administrada ao paciente antes mesmo do resultado da cultura ${ }^{(14)}$. Ainda assim, a limitação da cultura e dos métodos microscópicos para a detecção de infecção por $T$. vaginalis leva à necessidade de desenvolvimento de métodos mais sofisticados ${ }^{(35)}$.

$O$ advento da técnica de reação em cadeia de polimerase (PCR) tornou-se uma nova alternativa diagnóstica. Muitos testes com sensibilidade e especificidade próximas a 100\% têm sido desenvolvidos recentemente ${ }^{(29)}$. Apesar disso, não são utilizados rotineiramente no laboratório clínico devido a seu alto custo.

Várias técnicas baseadas na reação antígeno-anticorpo, que incluem aglutinação, fixação do complemento, hemaglutinação indireta, difusão em gel, imunofluorescência ${ }^{(11)} \mathrm{e}$ técnicas imunoenzimáticas (ELISA, do inglês enzyme-linked immunosorbent assay), têm sido utilizadas para demonstrar a presença de anticorpos anti-tricomonas ${ }^{(35)}$. Contudo, a resposta por anticorpos depende de vários fatores, como a natureza do antígeno, a forma livre ou inativa, a concentração no local e a duração da estimulação do sistema imune, não substituindo os exames parasitológico e cultural. Por isso os testes imunológicos não são rotineiramente usados no diagnóstico dessa DST ${ }^{(14)}$. 


\section{Epidemiologia e transmissão}

A tricomoníase é a DST não-viral mais comum no mundo, com 170 milhões de casos novos ocorrendo anualmente ${ }^{(44)}$. A incidência da infecção depende de vários fatores, incluindo idade, atividade sexual, número de parceiros sexuais, outras DSTs, fase do ciclo menstrual, técnicas de diagnóstico e condições socioeconômicas, entre outros $^{(35)}$. Diferenças no padrão de vida, nível educacional e higiene pessoal são fatores importantes que influenciam na incidência da infecção. A prevalência é alta entre os grupos de nível socioeconômico baixo, entre as pacientes de clínicas ginecológicas, pré-natais e em serviços de doenças sexualmente transmissíveis (DST). A freqüência de infecção é menor em mulheres casadas $(13,6 \%)$, quase 0 dobro em viúvas e solteiras $(22,7 \%$ a $25,6 \%)$ e três vezes maior (37\%) em mulheres divorciadas e separadas. $O$ baixo índice da tricomoníase em mulheres casadas é possivelmente devido ao fato de elas usarem contraceptivos com propriedades tricomonicidas. Muitos investigadores encontram um aumento da incidência da infecção de $T$. vaginalis em mulheres grávidas ${ }^{(24)}$. De acordo com Brown ${ }^{(7)}$, esse aumento pode ser devido à interrupção do uso de contraceptivos tricomonicidas, ao aumento na freqüência de relações sexuais e às mudanças hormonais que ocorrem durante a gravidez.

A prevalência da tricomoníase aumenta com a idade, um fenômeno que não é visto em outras DSTs, como gonorréia ou infecção por Chlamydia trachomatis. Isso é consistente com uma doença de longa duração, que é predominantemente assintomática ${ }^{(6)}$.

$\mathrm{O} T$. vaginalis é transmitido através da relação sexual e pode sobreviver por mais de uma semana sob o prepúcio do homem sadio após o coito com mulher infectada. O homem é o vetor da doença: com a ejaculação, os tricomonas presentes na mucosa da uretra são levados à vagina pelo esperma. Apesar disso, transmissão não-sexual teoricamente pode ocorrer em casos de duchas contaminadas, espéculos ou assento de vasos sanitários, segundo alguns autores. $\mathrm{O}$ organismo, não tendo a forma cística, é suscetível à dessecação e às altas temperaturas, mas pode viver, surpreendentemente, fora de seu hábitat por algumas horas, sob altas condições de umidade ${ }^{(13)}$. O T. vaginalis pode viver durante três horas na urina coletada e seis horas no sêmen ejaculado ${ }^{(13,36)}$.

Na recém-nascida, a tricomoníase pode ocorrer durante a passagem pelo canal do parto, em conseqüência da infecção materna, quando a mãe não tomou medidas profiláticas contra a parasitose durante a gestação ou quando ainda não iniciou o tratamento por não apresentar sintomas(27). Aproximadamente $5 \%$ das neonatas podem adquirir a tricomoníase verticalmente de suas mães infectadas. $\mathrm{Na}$ ocasião do parto, o epitélio escamoso da vagina da recémnascida sofre ação de estrógenos maternos e pode permitir a colonização do parasito. Entretanto esse efeito hormonal desaparece em poucas semanas após o parto, tornando o trato genital relativamente resistente à invasão do $T$. vaginalis. Dessa forma, bebês teriam condições de eliminar espontaneamente o parasito ${ }^{(8)}$. Pode não ser necessário tratar a tricomoníase levemente sintomática nas três primeiras semanas de vida porque a infecção é autolimitada ${ }^{(36)}$.

Embora o T. vaginalis seja transmitido por relação sexual, certas circunstâncias levam à crença de que, teoricamente, uma via não-venérea pode existir, explicando a tricomoníase em meninas, incluindo recém-nascidas, assim como em mulheres virgens ${ }^{(24)}$. A tricomoníase é incomum na infância (de 1 a 10 anos de idade), já que as condições vaginais (baixo $\mathrm{pH}$ ) não favorecem o desenvolvimento da parasitose. Portanto, quando encontrada na criança, deve ser cuidadosamente pesquisada, averiguando-se as possibilidades tanto de abuso sexual quanto de outras fontes de infecção, que não sexual(27) Entretanto, na préadolescência e na adolescência (dos 10 aos 18 anos de idade), a tricomoníase tem maior possibilidade de ser resultante de transmissão sexual. Além disso, a adolescência, especialmente, é caracterizada por alta atividade estrogênica que acompanha mudanças anatômicas e fisiológicas dos órgãos genitais, incluindo aumento do $\mathrm{pH}$ vaginal, que promove ambiente suscetível ao estabelecimento do T. vaginalis ${ }^{(27)}$.

A taxa de prevalência da infecção em homens é pouco conhecida, mas provavelmente é $50 \%$ a $60 \%$ menor que em mulheres ${ }^{(24)}$. A tricomoníase parece ser autolimitada em muitos homens, possivelmente devido à ação tricomonicida de secreções prostáticas ou à eliminação mecânica dos protozoários que se localizam na uretra durante a micção ${ }^{(36)}$. Os resultados dos estudos sobre a prevalência de $T$. vaginalis em homens são variados. Alguns autores relatam que a freqüência da tricomoníase em homens é relacionada com a freqüência de uretrites inespecíficas; $10 \%$ a $20 \%$ destes homens estão infectados por T. vaginalis. Uma incidência de $20 \%$ a $30 \%$ de infecções por tricomonas foi encontrada em homens cujas parceiras sexuais eram portadoras do protozoário flagelado. Uma correlação positiva existe entre presença desse parasito no trato urogenital masculino e infertilidade; cerca de $10 \%$ de homens estéreis estão infectados por $T$. vaginalis. 


\section{Terapia}

Incontestavelmente, o mecanismo de contágio da tricomoníase é a relação sexual, portanto o seu controle é constituído pelas mesmas medidas preventivas tomadas no combate às outras DSTs. Na abordagem dos pacientes com DST, são essenciais dados sobre data do último contato sexual, número de parceiros, hábitos e preferências sexuais, uso recente de antibióticos, métodos anticoncepcionais e história pregressa deste tipo de doença. Convém salientar que a presença de uma DST é fator de risco para outra ${ }^{(3)}$. Preconizam-se estratégias de prevenção às DSTs, tais como: 1) prática de sexo seguro, que inclui aconselhamentos que auxiliam a população a fazer as escolhas sexuais mais apropriadas para a redução do risco de contaminação com agentes infecciosos; 2) uso de preservativos; 3) abstinência de contatos sexuais com pessoas infectadas; e 4) limitação das complicações patológicas mediante a administração de tratamento imediato e eficaz, tanto para os casos sintomáticos como para os assintomáticos, ou seja, tratamento do casal, mesmo que a doença tenha sido diagnosticada em apenas um dos cônjuges ${ }^{(30,34,38)}$.

Em 1954, pela triagem de vários antibióticos, antimaláricos e amebicidas, foi descoberta a azomicina (2-nitroimidazol). Através da manipulação da estrutura química da azomicina foi sintetizado o metronidazol. Os fármacos mais utilizados contra as infecções pelos tricomonas são metronidazol, tinidazol, ornidazol, nimorazol, carnidazol, secnidazol e flunidazol ${ }^{(13,35)}$.

O metronidazol penetra na célula através de difusão e é ativado nos hidrogenossomos do T. vaginalis ${ }^{(35)}$. O metronidazol possui substituintes nitro e a ativação se dá pela redução destes grupos por ferredoxinas, encontradas somente em organismos anaeróbios, daí sua toxicidade seletiva ${ }^{(32)}$. Portanto o metronidazol pode ser considerado um pró-fármaco, pois requer ativação metabólica. A atividade antimicrobiana provavelmente resulta da formação de intermediários lábeis, quimicamente reativos, produzidos durante a redução do grupo nitro. O mecanismo pelo qual os intermediários lábeis matam organismos suscetíveis ainda não está totalmente esclarecido ${ }^{(26)}$. Estudos mostram que eles destroem as células através de reações com macromoléculas intracelulares, como DNA, proteínas e membranas ${ }^{(16,42)}$.

Muita atenção tem sido destinada aos relatos sobre um potencial carcinogênico devido ao fato de que o tratamento de longo prazo com altas doses de metronidazol poderia induzir tumores nos pulmões de animais. Entre- tanto dados clínicos sobre câncer provocado pelo uso de metronidazol são raros, e suas vantagens no tratamento da tricomoníase sobrepõem-se aos seus riscos. O fármaco não deve ser administrado indiscriminadamente, e as doses devem ser as mais baixas possíveis ${ }^{(36)}$. O metronidazol atravessa a barreira placentária e, por isso, não é indicado para o tratamento de mulheres infectadas que estejam no primeiro trimestre de gravidez ${ }^{(35)}$.

Embora o índice de cura seja excelente, freqüentemente ocorrem falhas no tratamento devido a reinfecção ou não-adesão à terapia. Outras razões propostas são baixa concentração de zinco no soro, baixa absorção do fármaco, distribuição não-efetiva do fármaco na região genital ou inativação do fármaco por bactérias presentes na flora vaginal das pacientes ${ }^{(35)}$. Nas duas últimas décadas foram descritas 20 linhagens de T. vaginalis resistentes ao metronidazol na Europa, onde passou a ser uma ameaça emergente ${ }^{(6)}$. O tratamento desses casos é problemático, podendo necessitar de altas concentrações de fármaco, aumentando o risco de toxicidade ${ }^{(35)}$.

Devido à freqüência da infecção na gravidez, à toxicidade do metronidazol e ao aparente desenvolvimento da resistência, alternativas terapêuticas aos 5-nitroimidazóis estão sendo pesquisadas ${ }^{(19,36)}$.

A vacinoterapia é uma nova tentativa de tratamento da tricomoníase. Cepas selecionadas de Lactobacillus acidophillus são comercializadas como vacina sob o nome de Solco-Trichovac e Gynatren. A média de cura, segundo alguns autores, depois de três a quatro doses da vacina se aproxima à dos nitroimidazóis ${ }^{(13)}$.

\section{Conclusões}

Embora o T. vaginalis tenha sido descrito pela primeira vez em 1836, por Donné, a pesquisa sobre este parasito só se iniciou no século 20. Estudos bioquímicos, fisiológicos, morfológicos e, mais recentemente, imunológicos e técnicas de biologia molecular têm fornecido muita informação sobre os aspectos clínicos e a patogênese do $T$. vaginalis. Entretanto os mecanismos da patogenicidade ainda não estão totalmente esclarecidos. A ação dos parasitos sobre as células do hospedeiro através da aderência e da citotoxicidade demonstra que mecanismos contato-dependentes e contato-independentes coexistem na patogênese da tricomoníase.

Apesar de a tricomoníase ser geralmente assintomática no homem, na mulher pode variar desde discreta a severa vaginite. Essa parasitose é a DST não-viral mais comum no 
mundo, sendo fortemente associada a várias complicações na gravidez, infertilidade, aumento na transmissão do HIV e indução de neoplasia intra-epitelial cervical.

O diagnóstico laboratorial da tricomoníase é essencial, não podendo ser baseado somente na apresentação clínica, pois a infecção poderia ser confundida com outras DSTs. As técnicas diagnósticas compreendem exame direto a fresco, preparações coradas, imunodiagnóstico, método da cultura e PCR. O método da cultura é o padrão-ouro, é simples de interpretar e apresenta alta sensibilidade. $O$ diagnóstico é indispensável para o tratamento apropriado e para a redução da propagação da infecção.

O metronidazol é o tratamento de escolha da tricomoníase, embora casos de resistência relatados constituam uma ameaça emergente. A terapia da tricomoníase torna-se eficaz somente quando os parceiros são simultaneamente tratados. O desenvolvimento de novos medicamentos que não pertençam à classe dos nitroimidazóis é necessário, assim como educação pública e programas de prevenção.

\section{Referências}

I. ALDERETE, J. F.; GARZA, G. E. Identification and properties of Trichomonas vaginalis proteins involved in cytoadherence. Infect Immun, v. 56, p. 28-33, 1988.

2.ALDERETE,J. F.et al. Only two of the Trichomonas vaginalis triplets AP5I adhesins are regulated by iron. Microbial Pathogen, v. 24, p. I-16, 1998.

3. AZULAY, M. M.; AZULAY, D. R. Doenças sexualmente transmissíveis. In: SCHECHTER, M.; MARANGONI, D. V. Doenças infecciosas: conduta diagnóstica e terapêutica. Rio de Janeiro: Guanabara Koogan, 1994. p. 335-57.

4. BARCHET, S. A new look at vaginal discharges. Obstet Gynecol, v. 40, p. 615-7, 1972.

5. BARRIO, A. G. et al. Biological variability in clinical isolates of Trichomonas vaginalis. Mem Inst Oswaldo Cruz, v. 97, p. 8936, 2002.

6. BOWDEN, F. J.; GARNETT, G. P. Why is Trichomonas vaginalis ignored? Sex Transm Infect, v. 75, p. 372-4, 1999.

7. BROWN, M. T. Trichomoniasis. Practitioner, v. 209, p. 639-44, 1972.

8. CONSOLARO, M.; SUZUKI, L.; MARQUES, E. Estudo da tricomoníase e a sua abordagem no diagnóstico colpocitológico. Rev Bras Anal Clin, v. 31, p. 25-8, 1999.

9. СОTCH, M. F. et al. Trichomonas vaginalis associated with low birth weight and preterm delivery. Sex Transm Dis, v. 24, p. 353-60, 1997.

I0. DE CARLI, G. A. Diagnóstico de laboratório da tricomoníase urogenital. Rev Bras Anal Clin, v. 24, p. 47-52, 1992.

I I. DE CARLI, G. A.; SARAIVA, P. J.; SARAIVA, O. J. Diagnóstico da tricomoníase pelo teste da imunofluorescência indireta. Rev Bras Anal Clin, v. 24, n. 4, p. 100-2, 1992.

12. DE CARLI, G.A. InPouchTVTM: um novo método de cultura para o diagnóstico da tricomoníase urogenital. Rev Bras Anal Clin, v. 25, p. 35-6, 1993.

13. DE CARLI, G. A. Trichomonas. In: NEVES, D. P. Parasitologia humana. São Paulo: Atheneu, 2000. p. 10 I-5.

14. DE CARLI, G.A. Exame de outros espécimes do trato intestinal e sistema urogenital. In: DE CARLI, G. A. Parasitologia clínica: seleção de métodos e técnicas de laboratório para o diagnóstico das parasitoses humanas. São Paulo: Atheneu, 200।.p. 165-99.
15. DE CARLI, G. A.;TASCA, T. Trichomonas vaginalis. In: DE CARLI, G. A. Parasitologia clínica: seleção de métodos e técnicas de laboratório para o diagnóstico das parasitoses humanas. São Paulo: Atheneu, 200 I. p. 453-67.

16. EDWARDS, D. I. Nitroimidazole drugs - action and resistance mechanisms. I. Mechanisms of action.J Antimicrob Chemother, v. 31, p. 9-20, 1993.

17. FLEMING, D. T.; WASSERHEIT, J. N. From epidemiological synergy to public health policy e practice: the contribution of other sexually transmitted diseases to sexual transmission of HIV infection. Sex Transm Inf, v. 75, p. 3- 17, 1999.

18. GARCIA,A. et al. Iron e contact with host cells induce expression of adhesins on surface of Trichomonas vaginalis. Mol Microbiol, v. 47, p. 1207-24, 2003.

19. GERBASE,A. C. et al. Global prevalence and incidence estimates selected curable STDs. Sex Transm Inf, v. 74, p. SI2-SI6, 1998.

20. GRAM, I. T. et al. Trichomonas vaginalis (TV) e human papilomavirus (HPV) infection and the incidence of cervical intraepithelial neoplasia (CIN) grade III. Cancer Causes Control, v. 3, p. 23I-6, 1992.

21. GROSTEIN, F.; GOLDMAN, M. B.; CRAMER D.W. Relation of tubal infertility to history of sexually transmitted diseases. Am J Epidemiol, v. I37, p. 577-84, 1993.

22. HEINE, P.; MCGREGOR, J. A. Trichomonas vaginalis: a reemerging pathogen. Clin Obstet Gynecol, v. 36: p. 137 44, 1993.

23. HOFFMAN, D. J. et al. Urinary tract infection with Trichomonas vaginalis in a premature newborn infant and the development of cronic lung disease.J Perinatol, v. 23, p. 59-6I, 2003.

24. HOGNIBERG, B. M.; BURGESS, E. Trichomonas of importance in human medicine including Dientamoeba fragilis. In: KREIER, J. P. Parasitic Protozoa. 2. ed. San Diego: Academic Press, 1994. v. 9, p. I-57.

25. KHARSANY, A. B. M. et al. The association between sexually transmitted pathogens and cervical intra-epithelial neoplasia in a developing community. Genitourin Med, v. 69, p. 357-60, 1993.

26. KULDA, J.Trichomonads, hydrogenosomes and drug resistance. Int J Parasitol, v. 29, p. 199-212, 1999. 
27. KURNATOWSKA, A.; KOMOROWSKA, A. Urogenital trichomoniasis in children. In: HONINGBERG, B. M. Trichomonads parasitic in humans. New York: Spring-Verlag, 1989. p. 246-73

28. LEHKER, M. W.; ALDERETE, J. F. Iron regulates growth of Trichomonas vaginalis and the expression of immunogenic trichomonad proteins. Mol Microbiol, v. 6, p. 123-32, 1991.

29. LEHKER, M.W.; ALDERETE, J. F. Biology of trichomonosis. Curr Opin Infect Dis, v. I3, p. 37-45, 2000.

30. LIMA, A. L. M. et al. Perguntas e respostas HIVIAids. São Paulo: Atheneu, 1996. p. 67.

31. LÓPEZ, L. B. et al. Strategies by which some pathogenictrichomonads integrate diverse signals in the decisionmaking process. An Acad Bras, v. 72, p. 173-86, 2000.

32. MENDZ, G. L.; MÉGRAUD, F. Is the molecular basis of metronidazole resistance in microaerophilic organisms understood? Trends Microbiol, v. I0, p. 370-5, 2002.

33. OHLEMEYER, C. L. et al. Diagnosis of Trichomonas vaginalis in adolescent females: InPouchTV cultures versus wet-mount microscopy. I Adolesc Health, v. 22, p. 205-8, 1998.

34. ORGANIZACIÓN MUNDIAL DE LA SALUD. Lucha contra las enfermedades de transmisión sexual. Ginebra, 1985. p. 23.

35. PETRIN, D. et al. Clinical and microbiological aspects of Trichomonas vaginalis. Clin Microbiol Rev, v. II, p. 300-17, 1998.

36. REIN, M. F. Trichomonas vaginalis. In: MANDELL, DOUGLAS, BENNET. Principles and practice of infectious diseases. New York: Churchill Livingstone, 1995. p. 2493-7.
37. RENDÓN-MALDONADO,J. G.; ESPINOSA-CANTELLANO, G. R. A.; MARTINEZ-PALOMO, A. Trichomonas vaginalis: in vitro phagocytosis of lactobacilli, vaginal epithelial cells, leuckocytes, and erythrocytes. Exp Parasitol, v. 89, p. 24I50, 1998.

38. ROBERT, J. Saúde pública, Aids e prostituição. In: NAUD, P. et al. Doenças sexualmente transmissíveis e Aids. Porto Alegre: Artes Médicas Sul, 1993. p. 287-8.

39. ROBERTSON, D. H. H. et al. Simultaneous isolation of Trichomonas vaginalis and collection of vaginal exudate. $\mathrm{Br}$ J Vener Dis, v. 45, p. 42-3, 1969.

40. ROSSET, I. et al. Scanning electron microscopy in the investigation on the in vitro hemolytic activity of Tricomonas vaginalis. Parasitol Res, v. 88, p. 356-9, 2002.

4I. SORVILLO, F. et al. Trichomonas vaginalis, HIV, and africanamericans. Emerg Infect Dis, v. 7, p. 927-32, 200 I.

42. TRACY, J. W.; WEBSTER, L. T. Drugs used in the chemoterapy of protozoal infections. In: Goodman and Gilman's. The pharmacological basis of therapeutics. New York: McGraw-Hill Companies, 1996. p. 995-8.

43. ZHANG, Z. F.; BEGG, C. B. Is Trichomonas vaginalis a cause of cervical neoplasia? Results from a combined analysis of 24 studies. Int J Epidemiol, v. 23, p. 682-90, 1994.

44. WORLD HEALTH ORGANIZATION. Global prevalence and incidence of selected curable sexually transmitted infections: overview and estimates. Geneva: WHO, 2001. p. 27-9. 